\title{
Presença de Pseudomonas spp em função de diferentes etapas da ordenha com distintos manejos higiênicos e no leite refrigerado
}

\author{
Presence of Pseudomonas spp in milking phases with different hygienic handling procedures \\ and in refrigerated milk
}

\author{
Celso Medina Fagundes ${ }^{1}$ Vivian Fischer ${ }^{2}$ Wladimir Padilha da Silva ${ }^{3}$ Nádia Carbonera $^{4}$ \\ Márcia Ribeiro Araújo ${ }^{3}$
}

\section{RESUMO}

O experimento foi conduzido, visando detectar Pseudomonas spp, em leite proveniente de propriedades leiteiras, de acordo com o sistema de produção. A presença de Pseudomonas spp, em leite cru recém - obtido e leite cru refrigerado $\left(5\right.$ a $\left.8^{\circ} \mathrm{C}\right)$, foi relacionada com as diversas etapas de ordenha em quatro propriedades leiteiras com diferentes sistemas de manejo higiênico. A contagem média de Pseudomonas spp, nas diversas fontes, nas propriedades, variou de 2,48 X $10^{2}$ UFC $\mathrm{mL}^{-1}$ (superfície de tetos) a $1,97 X 10^{4} \mathrm{UFC} \mathrm{mL}^{-1}$ (equipamentos), quando a higiene praticada foi adequada, mas de $8,71 \times 10^{2} \mathrm{UFC} \mathrm{mL}^{-1}$ (superfície de tetos) a $1,6 \times 10^{5} \mathrm{UFC} \mathrm{mL}^{-1}$ (leite refrigerado), quando o manejo foi inadequado.

Palavras-chave: leite cru, psicrotróficos, qualidade do leite.

\section{ABSTRACT}

The occurrence of Pseudomonas spp, in raw and refrigerated (e to $8^{\circ} \mathrm{C}$ ) bulk milk was related to milking steps at four dairy farms with distinct sanitary handling procedures. Average count for Pseudomonas spp at different sources, in the farms, varied from de $2.48 X 10^{2} \mathrm{CFU} \mathrm{mL}^{-1}$ (teats surface) to $1.97 \times 10^{4} \mathrm{CFU} \mathrm{mL}^{-1}$ (equipments), when sanitary procedures were adequate, but from de $8.71 X 10^{2} \mathrm{CFU} \mathrm{mL} \mathrm{m}^{-1}$ (teats surface) to $1.6 \times 10^{5} \mathrm{CFU} \mathrm{mL}^{-1}$ (refrigerated milk) when sanitary procedures were inadequate.

Key words: milk quality, psycrotrophics, raw milk.

\section{INTRODUÇÃO}

O tema qualidade do leite é bastante complexo dado à diversidade do sistema de produção de propriedades e produtores de leite tornando difícil a implementação de pagamento diferenciado pelas indústrias. No Programa Nacional de Melhoria na Qualidade do Leite, o qual está sendo implantado, dentre inúmeros aspectos, destacam-se os físicoquímicos, sensoriais e microbiológicos. Desses fatores, a qualidade microbiológica é fundamental como indicativo de saúde do rebanho e da higiene praticada na propriedade, determinando assim o potencial nutricional do leite e da segurança alimentar. Portanto, é fundamental a modernização no setor agroindustrial laticinista, incluindo inúmeras mudanças, entre elas, o armazenamento sob refrigeração no local de ordenha e o sistema de coleta a granel. Estas práticas estão sendo criadas pelo Ministério da Agricultura, Pecuária e Abastecimento, através da Instrução Normativa (nº 51 de 18 de setembro de 2002), a qual implanta o sistema de refrigeração do leite e a granelização no transporte em nível de propriedades leiteiras, que vigorará a partir de janeiro de 2005.

Com a implantação desta instrução normativa, ocorrerá, inexoravelmente, o término do sistema de coleta de leite em latões, surgindo uma nova realidade com o uso de resfriadores e o transporte do

${ }^{1}$ Departamento de Ciência e Tecnologia Agroindustrial (DCTA) Faculdade de Agronomia Eliseu Maciel (FAEM) Universidade Federal de Pelotas (UFPel), Campus Universitário s/n CP. 354, 96010-900, Pelotas, RS, Brasil. E-mail: fagundes@ufpel.tche.br. Autor para correspondência.

${ }^{2}$ Departamento de Zootecnia (FAEM/UFPel), Pelotas, RS, Brasil. E-mail: vfried@ufpel.tche.br.

${ }^{3}$ DCTA/FAEM/UFPel, Pelotas, RS, Brasil.

${ }^{4}$ Química em Alimentos UFPel, Pelotas, RS, Brasil. 
leite em caminhões isotérmicos, se bem que nas regiões sul e sudeste do Brasil, isto já vem ocorrendo, embora em caráter até certo ponto experimental.

A racionalização da coleta e do transporte do leite até a indústria é uma tendência mundial, beneficiando toda a cadeia do leite. A refrigeração do leite, imediatamente após a ordenha, visa diminuir a multiplicação de bactérias mesófilas que causam a acidificação. Entretanto, isso favorecerá a microbiota psicrotrófica que estiver presente na matéria-prima, o que poderá provocar diversas alterações no leite e seus derivados.

A refrigeração do leite-, por si só, não é garantia de qualidade. É extremamente importante que o leite cru seja obtido em condições higiênicosanitárias adequadas para diminuir a contaminação inicial e, desta forma, a redução -da temperatura pode manter a contagem microbiana em níveis baixos. Salienta-se que, quanto maior o tempo de estocagem sob baixas temperaturas $\left(7\right.$ a $\left.10^{\circ} \mathrm{C}\right)$ de um leite apresentando alta contagem inicial de microrganismos, maiores serão as possibilidades de alterações no produto final (leite pasteurizado, leite ultra pasteurizado e queijos), pela ação de microrganismos psicrotróficos, com o predomínio do gênero Pseudomonas spp (MUIR, 1996). Este gênero microbiano, além de ser o mais prevalente, apresenta espécies capazes de produzir enzimas extracelulares resistentes às temperaturas comumente utilizadas no processamento térmico de leite e derivados (GRIFFITHS, 1990). Portanto, faz-se necessária uma avaliação destas novas medidas sobre o impacto na qualidade do produto, especialmente do papel fundamental da temperatura e tempo de armazenamento no maior ou menor índice de crescimento microbiano.

A refrigeração do leite, logo após a ordenha, visa diminuir a multiplicação microbiana, entretanto, sua eficiência é maximizada se associada a outros fatores, especialmente de ordem higiênica. Nesse processo de conservação do leite pelo frio, recomendase que, na segunda hora após a ordenha, a temperatura deva estar a $4^{\circ} \mathrm{C}$, condição esta que não impede a proliferação de microrganismo psicrotróficos. $\mathrm{Na}$ grande maioria das propriedades leiteiras, a temperatura de refrigeração oscila entre 5 a $10^{\circ} \mathrm{C}$, o que configura, um "resfriamento marginal do leite" (SANTOS \& LARANJA, 2001), contribuindo para multiplicação de microrganismos psicrotróficos, resultando na queda de qualidade de leite e derivados. SUHREN (1989) afirma que, entre os organismos psicrotróficos, o gênero mais freqüentemente isolado do leite refrigerado é Pseudomonas, sendo as espécies $\boldsymbol{P}$. fluorescens, $\boldsymbol{P}$. fragi, $\boldsymbol{P}$. putida e $\boldsymbol{P}$. putrefaciens as que têm papel relevante na diminuição da qualidade do leite fluído e demais derivados lácteos. No leite "in natura" refrigerado a espécie $\boldsymbol{P}$. fluorescens é predominante sobre as demais espécies (DESMASURES \& GUEGUEN, 1997; ENEROTH et al., 2000; RYSER, 1999). Segundo MUIR (1996), no leite recém-obtido, Pseudomonas spp. está presente em torno de $10 \%$ da microbiota total, mas, em leite mantido sob refrigeração, essas bactérias têm predominância sobre as demais espécies presente quer no leite "in natura“ quer no beneficiado.

A contaminação por Pseudomonas, inclusive na água que abastece a sala de ordenha, fará com que ocorra a sua presença no leite, bem como o seu desenvolvimento em condições de refrigeração (COUSIN \& BRAMLEY, 1991). Além disso, foi detectada a presença de Pseudomonas spp. em superfície de tetos, em contagens variáveis, na faixa de de $2,1 \times 10^{4}$ a 2,2x106 UFC mL ${ }^{-1}$ (DESMASURES \& GUEGUEN,1997).

Além destas fontes já citadas, as variações sazonais exercem papel relevante na freqüência e nas espécies de microrganismos psicrotróficos encontrados no leite, com decréscimo na contagem de psicrotróficos no leite produzido no verão em relação à produção de inverno (COUSIN 1981). O mesmo autor relata uma maior concentração de psicotróficos no leite de vacas estabuladas comparado com o leite produzido por animais mantidos em pastagens durante a primavera. A microbiota psicrotrófica no leite "in natura" produzido por vacas estabuladas consiste principalmente de Pseudomonas, Arthrobacter e Micrococcus, entretanto o Flavobacterium é dominante no leite de vacas mantidas em sistema a pasto (COUSIN \& BRAMLEY, 1991).

A contagem de coliformes e não coliformes (Pseudomonas spp) podem ser utilizadas como parâmetro para avaliar a qualidade do leite (JAYARAO \& WANG, 1999). Esses autores verificaram que, de um total de 131 propriedades leiteiras (em Dakota e Minnesota), foram isoladas 234 cepas, e destas, 116 pertenceram ao gênero Pseudomonas spp, dentre as quais $\boldsymbol{P}$. fluorescens foi a espécie predominante (29,9\%). GOMES (1995), detectou a presença de Pseudomonas spp em leite cru tipo ' $B$ ' produzido em cinco propriedades de Botucatu (SP), encontrando contagem média de 4,8 x $10^{4} \mathrm{UFC} \mathrm{mL}^{-1}$. PINTO et al (2003) coletaram 46 amostras de leite cru refrigerados produzido por produtores da Zona da Mata Mineira em quatro silos industriais, e detectaram 147 colônias de bactérias psicrotróficas, as quais foram identificadas como Pseudomonas spp.

O objetivo deste trabalho foi quantificar o número de unidades formadoras de colônia de 
Pseudomonas spp nas mãos dos ordenhadores, equipamentos, água e superfície de tetos, em propriedades leiteiras com distintos manejos sanitários e nos leites cru recém obtido e refrigerado.

\section{MATERIAL E MÉTODOS}

Foram coletadas amostras de leite $(500 \mathrm{~mL})$ em tanques e baldes de ordenhadeiras, procedentes de quatro propriedades leiteiras, selecionadas conforme o manejo higiênico, sendo duas consideradas adequadas e duas inadequadas. As amostras foram coletadas durante o período de um ano, isto é, duas amostras por propriedade em cada estação do ano. As amostras foram colocadas em frascos esterilizados, após homogeneização no balde da ordenhadeira e/ou tarros e acondicionados em caixas térmicas contendo gelo.

Nas mesmas ocasiões, foram coletadas também amostras de água, equipamentos, superfície de tetos e mãos dos ordenhadores, a fim de verificar a existência de microrganismos nestas possíveis fontes de contaminação.

As amostras de água (sem cloração) utilizadas nas propriedades estudadas foram coletadas diretamente das torneiras e/ou mangueiras e colocadas em frascos de $10 \mathrm{~mL}$, esterilizados, contendo $0,1 \mathrm{~mL}$ de tiosulfato de sódio $0,1 \%$. O número de amostras de água, nas quatro propriedades, durante todo o experimento, foram trinta e duas, sendo oito amostras por propriedade.

As amostras oriundas das mãos dos manipuladores foram coletadas através da lavagem das mãos por aproximadamente $1 \mathrm{~min}$, dentro de embalagem plástica esterilizada contendo $100 \mathrm{~mL}$ de solução salina $0,85 \%$. O número de amostras coletadas foi idêntico ao total de amostras de água, o mesmo acontecendo com as amostras retiradas de equipamentos e/ou utensílios.

As amostras procedentes de utensílios e/ ou equipamentos e de superfície de pele dos tetos dos animais foram amostradas através de swabs, os quais foram mantidos em tubos de ensaios esterilizados, contendo solução salina $0,85 \%$ esterilizada. Para aquelas oriundas da superfície de pele dos tetos dos animais, cada tubo de ensaio representou um grupo de cinco vacas, utilizando-se um swab por superfície de tetos em cada animal. Em cada uma das propriedades, foram coletadas amostras de tetos de vinte e cinco vacas. O total de amostras coletadas durante o desenvolvimento da pesquisa foi cento e sessenta, sendo quarenta por propriedade.

Imediatamente após a coleta, todas as amostras foram acondicionadas em caixa isotérmica contendo gelo e mantidas sob resfriamento até o momento da análise. Na sua recepção no laboratório do Departamento de Ciência e Tecnologia Agroindustrial da Faculdade de Agronomia Eliseu Maciel, na Universidade Federal de Pelotas, foram retiradas alíquotas de $250 \mathrm{~mL}$ das amostras de leite para frascos esterilizados, as quais foram estocadas sob refrigeração $\left(5\right.$ a $8{ }^{\circ} \mathrm{C}$ ) em geladeira, durante 48 horas, simulando o período de manutenção do leite sob resfriamento nas propriedades. Após esse período, foram submetidas às mesmas análises realizadas no leite recém-obtido. O total de amostras coletadas em todo o experimento foi idêntico ao leite recém-obtido.

As propriedades leiteiras, onde a pesquisa foi desenvolvida, foram classificadas de acordo com o manejo higiênico utilizado, em adequadas (propriedades 1 e 2) e inadequadas (propriedades 3 e 4). Para esta classificação, levaram-se em consideração as práticas de higiene utilizadas pré e pós ordenha somadas às condições de infra-estrutura desses estabelecimentos.

Na enumeração de Pseudomonas spp, foi utilizado o meio de cultura Pseudomonas Agar Base (CM 559- Oxoid), com adição de suplemento (CFC-SR 103-Oxoid). As amostras de leite recém-obtido, do leite refrigerado (48 horas 5 a $8^{\circ} \mathrm{C}$ ) e das diversas fontes de contaminação amostradas nas propriedades, após diluições decimais $\left(10^{1,} 10^{2}, 10^{3}\right)$ em água salina (0,85\%), foram inoculadas no meio de cultura, espalhadas com alça de Drigalski, sendo imediatamente incubadas a temperaturas entre 28 a $30^{\circ} \mathrm{C}$, e mantidas nessa temperatura durante 48 horas. Ao fim desse período, fazia-se a leitura e interpretação.

O delineamento experimental adotado baseou-se em arranjo fatorial completamente casualizado. Os dados obtidos foram transformados pela aplicação de log natural (nº de Pseudomonas spp +1) para obter uma distribuição normal de dados, testado segundo o procedimento univariate do SAS. Nas tabelas, porém, são apresentados os valores não transformados a fim de facilitar a sua interpretação.

Os dados transformados foram submetidos à análise de variância considerando os seguintes efeitos: estação do ano ( $\mathrm{n}=4$, primavera, verão, outono, inverno), higiene ( $n=2$, adequada e inadequada), propriedades hierarquizadas dentro do nível de higiene ( $n=4$, sendo duas propriedades com higiene adequada e duas inadequadas), e as fontes de contaminação ( $n=6$, leite recém-obtido e leite cru refrigerado, superfície de tetos, mãos, água e equipamentos), e as interações E.H, E.F e H.F, conforme modelo matemático:

$\mathrm{Y}_{\mathrm{ijkl}}=\mu+\mathrm{Ei}+\mathrm{Hj}+\mathrm{P}(\mathrm{h}) \mathrm{ij}+\mathrm{Fk}+\mathrm{EHij}+\mathrm{EFik}+\mathrm{HFik}+$ Eijkf.

Onde: 
$\mu=$ média geral do experimento

$\mathrm{E}_{\mathrm{i}}=$ efeito de estação do ano $(\mathrm{GL}=3)$

$\mathrm{H}_{\mathrm{j}}=$ efeito higiene $(\mathrm{GL}=1)$

$\mathrm{P}(\mathrm{h})_{\mathrm{ji}}=$ efeito propriedade em relação a higiene praticada (GL=2)

$\mathrm{F}_{\mathrm{k}}=$ efeito fontes de contaminação(GL=5)

$\mathrm{E}_{\mathrm{hij}}^{\mathrm{k}}=$ efeito da interação higiene e estação $(\mathrm{GL}=3)$

$E_{\text {fik }}=$ efeito da interação estação e fontes de contaminação (GL=15)

$\mathrm{H}_{\text {fij }}$ = efeito da interação higiene e fontes e fontes de contaminação (GL=5)

$\mathrm{E}_{\mathrm{ijkf}}=$ erro experimental

A separação das médias foi realizada através do Lsmeans e o nível de significância adotado foi de $0,05 \%$

\section{RESULTADOS E DISCUSSÃO}

Nas tabelas 1 e 2 estão expressos, respectivamente, os valores de probabilidade segundo os efeitos, para a ocorrência e contagens de Pseudomonas spp, obtidas em propriedades leiteiras com distintos manejos na ordenha. Verificam-se diferenças na contagem Pseudomonas spp em relação aos efeitos: nível de higiene, propriedade, fonte de contaminação e na interação entre nível de higiene $\mathrm{x}$ fonte de contaminação (Tabela 1). A contagem de Pseudomonas spp na superfície dos tetos foi menor $(\mathrm{P}=0,0669)$ nas propriedades com manejo higiênico adequado em relação às inadequadas, o que parece estar relacionada à forma de higienização conduzida nas propriedades. A propriedade 1 efetua lavagem dos tetos com água e secagem com papel toalha e os animais permanecem em pastejo permanente por 24 horas, reduzindo, desta forma, a contaminação que possivelmente ocorreria no caso de os animais permanecerem ao redor do estábulo. A propriedade 2, que utiliza sistema de confinamento, executa uma boa higienização pré-ordenha (pré-dipping). Esses procedimentos, embora distintos, colaboraram para uma menor contaminação nessa fonte. SANTOS \& LARANJA (2001) encontraram resultados de contaminação superiores nessa fonte (entre 2,1 x $10^{4}$ e $2,2 \times 10^{6} \mathrm{UF} \mathrm{mL}^{-1}$ ), entretanto os autores não se referem ao manejo pré-ordenha praticado no experimento.
A contaminação da água por Pseudomonas spp foi menor nas propriedades com manejo higiênico adequado em relação àquelas classificadas como inadequadas (Tabela 2). Nas propriedades 1 e 2, a água procede de poços, enquanto nas propriedades 3 e 4, esta é oriunda de açudes e/ou lagoas. A importância da qualidade microbiológica da água utilizada durante a pré-ordenha também foi salientada por DESMASURES \& GUEGUEN (1997), COUSIN \& BRAMLEY (1981), SANTANA et al. (2001), tendo em vista que entra em contato com todos os equipamentos e superfícies de utensílios inerentes à ordenha.

Entretanto, a avaliação da contaminação das mãos dos ordenhadores e equipamentos nas propriedades com manejo higiênico adequado não mostrou diferença estatística significativa entre elas, conforme pode ser observado na tabela 2. SANTOS \& LARANJA (2001) encontraram índices de contaminação

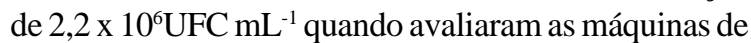
ordenha, sem citar as condições de higiene empregadas na higienização dos equipamentos. Os resultados obtidos por GOMES (1995), em propriedades produtoras de leite tipo “ $\mathrm{B}$ ” da região de Campinas, SP

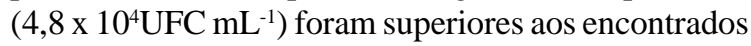
nas propriedades leiteiras com higiene adequada avaliadas neste estudo (Tabela 2), evidenciando a necessidade de práticas higiênicas corretas, independente do tipo de leite produzido.

A contagem de Pseudomonas spp, tanto no leite recém obtido $\left(1,08 \times 10^{5} \mathrm{UFC} \mathrm{mL}^{-1}\right)$ como no leite cru refrigerado $\left(1,6 \times 10^{5} \mathrm{UFC} \mathrm{mL}^{-1}\right)$ obtidos nessas propriedades foi superior quando comparada com aquela oriunda de propriedades leiteiras com higiene adequada. Isso se deve, provavelmente, aos fatores predisponentes, decorrente do manejo higiênico préordenha, onde a água tem papel fundamental, haja vista esta não ser potável. Embora a água utilizada nas propriedades com manejo higiênico adequado também não seja oriunda da rede pública de abastecimento, portanto não tratada, pode-se observar através da tabela 2, que o índice de Pseudomonas spp na água das propriedades com manejo inadequado foi superior, o que, provavelmente, reflete a qualidade da água utilizada.

Tabela 1 - Valores da probabilidade $(P<0,05)$ segundo os efeitos estação, higiene, propriedades, fontes e interações para ocorrência de Pseudomonas spp, no leite bovino, Pelotas, 2002/2003.

\begin{tabular}{llllllll}
\hline Microrg. $^{1}$ & Estação & Higiene & Prop & Fonte & E x H H $^{3}$ & E x F $^{5}$ & H x F $^{6}$ \\
\hline Pseud. $^{2}$ & 0,1939 & 0,0001 & 0,0001 & 0,0001 & 0,7323 & 0,4976 & 0,0032 \\
\hline
\end{tabular}

${ }^{1}$ Microrganismo - ${ }^{2}$ Pseudomonas $-{ }^{3}$ Propriedade $-{ }^{4}$ Estação $\mathrm{x}$ higiene $-{ }^{5}$ Estação $\mathrm{x}$ fonte $-{ }^{6}$ Higiene $\mathrm{x}$ fonte 
Tabela 2 - Variação na enumeração de Pseudomonas spp. em diferentes fontes de contaminação em propriedades leiteiras com distintos manejos de ordenha, Pelotas 2002/2003.

\begin{tabular}{|c|c|c|c|c|}
\hline \multirow[t]{2}{*}{ Fontes } & \multicolumn{2}{|c|}{ Pseudomonas spp. (UFC. $\mathrm{mL}^{-1}$ ) Higiene adequada } & \multicolumn{2}{|c|}{ Pseudomonas spp.(UFC. $\mathrm{mL}^{-1}$ ) Higiene inadequada } \\
\hline & Média $^{1}$ & $\mathrm{CV}^{2}(\%)$ & Média $^{1}$ & $\begin{array}{c}\text { Comparação higiene } \\
\text { p/fonte }\end{array}$ \\
\hline Superfície de tetos & $2,48 \times 10^{2 b}$ & 17,7 & $8,71 \times 10^{2 a}$ & 0,0369 \\
\hline Mãos & $4,36 \times 10^{3 \mathrm{a}}$ & 21,6 & $6,26 \times 10^{3 a}$ & 0,3247 \\
\hline Água & $4,3 \times 10^{3 \mathrm{~b}}$ & 18,6 & $1,49 \times 10^{4 \mathrm{a}}$ & 0,0196 \\
\hline Equipamentos & $1,97 \times 10^{4}$ a & 14,6 & $1,17 \times 10^{4 a}$ & 0,1337 \\
\hline Leite recém-obtido & $7,33 \times 10^{3} \mathrm{~b}$ & 17,7 & $1,08 \times 10^{5 a}$ & 0,0041 \\
\hline Leite refrigerado ${ }^{3}$ & $1,02 \times 10^{4 \mathrm{~b}}$ & 1,6 & $1,6 \times 10^{5 a}$ & 0,0004 \\
\hline
\end{tabular}

1 - Enumeração de Pseudomonas spp (valores não transformados).

2 - a, b, Médias na mesma linha seguidas por letras distintas diferem segundo Lsmeans (DMS Fischer) em nível de 0,05 \%.

$3-5$ a $8^{\circ}$ por 48 horas.

A contagem elevada de Pseudomonas spp, tanto em leite recém-obtido quanto em leite refrigerado, naquelas propriedades leiteiras com práticas de higiene inadequada também foram decorrentes de outras fontes de contaminação, como superfícies de tetos, como pode ser visualizado na tabela 2 . A primeira tem como principal fator de contaminação a diversidade do material de cama, acrescido de lama e fezes, que podem ficar aderidos à superfície de tetos, conforme relatam COUSIN \& BRAMLEY (1981).

Houve uma maior concentração de Pseudomonas spp em leite cru refrigerado, quando comparado com o leite recém-obtido (Tabela 2), o que vem ao encontro dos resultados encontrados por SANTOS \& LARANJA(2001), MUIR (1996) e RYSER (1999). Isto se deve às temperaturas e aos tempos de estocagem praticados no experimento, que facilitam o desenvolvimento de bactérias psicrotróficas, como é o caso de Pseudomonas spp, que tem o seu tempo de geração menor que as bactérias mesófilas também presentes no leite. Salienta-se, entretanto, que naquelas propriedades cujo manejo higiênico é deficitário, a contagem média de Pseudomonas spp., tanto no leite recém-obtido, quanto no leite refrigerado, foi superior ao encontrado no leite obtido nas propriedades 1 e 2 .

\section{CONCLUSÃO}

Nas propriedades avaliadas, o manejo sanitário pode reduzir efetivamente a contagem de Pseudomonas spp sobretudo na superfície dos tetos, leite recém obtido e resfriado.

\section{AGRADECIMENTOS}

Ao Conselho Nacional de Desenvolvimento Científico e Tecnológico (CNPq) pela concessão de bolsa ao pesquisador Fischer.

\section{REFERÊNCIAS}

COUSIN, M.A,; BRAMLEY, A.J. The microbiology of raw milk. In: ROBINSON, R.K. Dairy microbiology of milk. London: Applied Science Publishers, 1981. p.119-163.

DESMASURES, N.; GUEGUEN, M. Monitoring the microbiology of high quality milk by monthly sampling over 2 years. Journal of Dairy Research, v.64, p.271-280, 1997.

ENEROTH, A et al. Contamination routes of Gram-negative spoilage bacteria in the production of pasteurized milk evaluated by randomly amplified polymorphic DNA (RAPD). International Dairy Journal, v.10, p.325-331, 2000.

GOMES, M.I.F.V. Contribuição ao estudo da atividade proteolítica residual sobre a estabilidade protéica do leite esterilizado “Longa-Vida”. 1995. 103f. Tese (Doutorado em Tecnologia de Alimentos) - Faculdade de Engenharia de Alimentos, Universidade Estadual de CampinasSP.

GRIFFITHS, M.W. Toxin production by psychrotrophic Bacillus spp present in milk. Journal of Food Protection, v.59, n.9, p.790-792, 1990.

JAYARAO, B.M.; WANG, L. A study on the prevalence of Gram-negative bacteria in bulk tank milk. Journal Dairy Science, v.88, p.2620-2624, 1999.

MUIR, D.D. The shelf-life of dairy products: factors influencing raw and fresh products. Journal of the Society of Dairy Technology, v.49, p.24-32, 1996.

PINTO, C.L.O. et al. Potencial deteriorador de bactérias psicrotróficas Gram-negativas isoladas de amostras de leite cru refrigerado. Revista do Instituto de Laticínios Cândido Tostes, v.58. n.333, p.49-54, 2003.

RYSER, E. Microrganisms of importance in raw milk. Michigan Dairy Review, v.8, p.7-9, 1999.

SANTANA, E.H.V et al. Microrganismos psicrotróficos em leite. Revista Higiene Alimentar, v.15, n.88, p.27-33, 2001.

SANTOS, M.V.; LARANJA, F.L.F. Importância e efeito de bactérias psicrotróficas sobre a qualidade do leite. Revista Higiene Alimentar, v.15, n.82, p.13-19, 2001.

SUHREN, G. Producer microorganism. In: MCKELLER, R.C. Enzimes of psychrotrophs in raw food. Boca Raton: CRC, 1989. 310p. 